\title{
Overcoming Host- and Pathogen-Mediated Resistance in Tomato and Tobacco Maps to the M RNA of Tomato spotted wilt virus
}

\author{
K. Hoffmann, ${ }^{1}$ W. P. Qiu, ${ }^{2}$ and J. W. Moyer ${ }^{3}$ \\ ${ }^{1}$ Department of Virology, DLO Research Institute for Plant Protection (IPO-DLO), P. O. Box 9060, $6700 \mathrm{GW}$ \\ Wageningen, The Netherlands; ' ${ }^{2}$ Department of Plant Pathology and Microbiology, Texas A\&M University, \\ College Station 77843, U.S.A.; ${ }^{3}$ Department of Plant Pathology, North Carolina State University, Raleigh \\ 27695-7616, U.S.A. \\ Accepted 28 October 2000.
}

\begin{abstract}
A viral genetic system was used to map the determinants of the ability of Tomato spotted wilt virus (TSWV) to overcome the $R$ gene $(S w-5)$ in tomato and the resistance conferred by the nucleocapsid gene of TSWV ( $N$ gene) in tobacco. A complete set of reassortant genotypes was generated from TSWV isolates A and D. TSWV-A was able to overcome the $S w-5$ gene in tomato and the TSWV $N$ gene in tobacco, whereas TSWV-D was repressed by both forms of resistance. The ability to overcome both forms of resistance was associated with the M RNA segment of TSWV-A $\left(\mathrm{M}_{\mathrm{A}}\right)$. Overcoming the $\mathrm{Sw}-5$ gene was linked solely to the presence of $M_{A}$, and the ability of $M_{A}$ to overcome the TSWV $N$ gene was modified by the $L$ RNA and the S RNA of TSWV-A, which is consistent with previous reports that suggest that the nucleocapsid gene is not the primary determinant for overcoming the nucleocapsid-mediated resistance. Sequence analysis of the $M$ RNA segment of TSWV-A, -D, and the type isolate BR-01 revealed multiple differences in the coding and noncoding regions, which prevented identification of the resistancebreaking nucleotide sequences.
\end{abstract}

Tomato spotted wilt virus (TSWV) has become increasingly important as a result of significant economic losses in many agronomic and ornamental crops worldwide. TSWV is the type member of the genus Tospovirus in the family Bunyaviridae (Elliott 1990). Until recently, TSWV was considered to be the only member of the Tospovirus genus, although diversity had been reported among isolates. The discovery of Impatiens necrotic spot virus (Law and Moyer 1990; Law et al. 1991) provided the basis for distinguishing distinct species in the Tospovirus genus. Subsequently, diversity within species also has been described at the molecular and biological level (Adam et al. 1993; De Avila et al. 1993; Feldhoff et al. 1997). TSWV has long been known to exist as complex populations

Corresponding author: J. W. Moyer; Telephone: +1-919-515-7984; Fax: +1-919-515-7716; E-mail: james_moyer@ncsu.edu

Nucleotide sequence data reported in this paper have been submitted to the GenBank nucleotide sequence database and assigned accession nos. AF20497 and AF20498. of stable isolates in nature (Best 1954; Best and Gallus 1953; Norris 1946). The ability of TSWV to multiply in its thrips vector increases the opportunity for genetic diversification of populations (Ullman et al. 1993; Wijkamp et al. 1993). The tripartite genome organization of the family Bunyaviridae allows closely related viruses to exchange genetic information through the reassortment of whole genome segments to form a distinct isolate (Elliott 1996). The genetic reservoir present in the heterogeneous virus populations combined with the reassortment mechanism provide conditions conducive for rapid adaptation of virus populations to resistant host plants.

Tospoviruses have enveloped, quasispherical particles that contain tripartite RNA segments, designated L (8.9 kb), M (4.9 kb), and S (2.9 kb) (De Haan et al. 1990; De Haan et al. 1991; German et al. 1992; Law et al. 1992). The L RNA has one open reading frame (ORF) in the viral complementary sense that encodes a $330-\mathrm{kDa}$ protein, putatively designated the RNA-dependent RNA polymerase (Adkins et al. 1995; De Haan et al. 1991; Van Poelwijk et al. 1997). The M RNA (Kormelink et al. 1992; Law et al. 1992) and the S RNA (De Haan et al. 1990) each contain two ORFs in ambisense orientation. The M RNA and S RNA encode a nonstructural protein, NSm and NSs, at the $5^{\prime}$ end in viral sense, respectively. Whereas no biological function has yet been assigned to the NSs protein, the NSm protein is thought to be involved in cell-to-cell movement (Storms et al. 1995). M RNA and S RNA contain a second ORF in the viral complementary sense, separated from the first ORF by a highly structured, adenineuracil-rich intergenic region over 500 nucleotides (nt) in length (De Haan et al. 1990; Law et al. 1992). The 3' terminal ORF on the M RNA encodes the precursor of the $G_{1}$ and $G_{2}$ structural proteins that reside in the outer envelope of the virion (Adkins et al. 1996; Law et al. 1992). The 3' terminal ORF on the S RNA encodes the nucleocapsid protein (N protein) that encapsidates the viral RNA (De Haan et al. 1990). The $\mathrm{N}$ protein gene has been used widely as the source of pathogen-derived resistance (Kim et al. 1994; Pang et al. 1992; Pang et al. 1996; Sherman et al. 1998; Ultzen et al. 1995; Vaira et al. 1995).

TSWV routinely defeats resistance in commercial crops such as tomato (Cho et al. 1996; Latham and Jones 1998) and pepper (Hobbs et al. 1994; Moury et al. 1997) within a short 
time. Resistance against TSWV in tomato was first reported in Lycopersicon pimpinellifolium (Samuel et al. 1930). The resistance was controlled by five genes $(1 a, 1 b, 2,3$, and 4), which individually conferred resistance, although insensitivity soon developed in TSWV. The $S w-5$ gene, first identified in $L$. peruvianum (Smith 1944), is more stable and less isolate specific (Boiteux and De B. Giordano 1993; Stevens et al. 1992). Tomato plants carrying the $S w-5$ gene resist systemic infection by TSWV. Therefore, the $S w-5$ gene has been used widely in breeding programs (Cho et al. 1989; Paterson et al. 1989). The $S w-5$ gene is a single dominant gene (Stevens et al. 1992) that confers a hypersensitive response to challenge TSWV isolates sensitive to the gene, indicating a gene-for-gene interaction (Staskawicz et al. 1995). The $S w-5$ locus has been mapped genetically (Folkertsma et al. 1999; Stevens et al. 1995) and the sequence corresponding to the $S w-5$ gene has been determined (Brommenschenkel and Tanksley 1997). Recently, naturally occurring resistance-breaking isolates of TSWV have been recovered from tomato cultivars containing the $S w$ 5 gene in the field (Cho et al. 1996) and greenhouse (Latham and Jones 1998). If the latter isolates were subjected only to four passages on resistant tomato cultivars, stable resistancebreaking isolates were obtained. These resistance-breaking isolates were highly competitive in a mixed infection of the original field isolates and on a susceptible tomato line (Latham and Jones 1998).

When host resistance against TSWV is overcome, pathogen-derived resistance for virus control may provide a significant supplement to traditional strategies (Goldbach and Haan 1993). Transgenic resistance to TSWV was first introduced into tobacco by Gielen et al. (1991) with the use of the $N$ gene, followed by a variety of other crops such as lettuce, tomato, and chrysanthemum (Kim et al. 1994; Pang et al. 1992; Pang et al. 1996; Sherman et al. 1998; Ultzen et al. 1995; Vaira et al. 1995). In addition to the $N$ gene, NSm gene sequences also confer resistance to TSWV (Prins et al. 1997). Transgenic resistance is independent of the level of transgene expression (Gielen et al. 1991; MacKenzie and Ellis 1992; Pang et al. 1992; Pang et al. 1994; Prins et al. 1997), indicating an RNA-mediated resistance as a result of posttranscriptional gene silencing, which has been proposed as the basis for TSWV transgene-mediated resistance (Pang et al. 1996; Pang et al. 1997; Prins et al. 1996). Recent studies have shown that TSWV is able to overcome the transgene-mediated resistance through natural selection for resistance-breaking isolates in the field (Herrero et al. 2000; Jankulova et al. 1999) and through genomic reassortment under experimental conditions (Qiu et al. 1998). The genetic analysis of the viral populations from serial passages of two suppressed isolates, TSWV-10 and TSWV-D, on TSWV nucleocapsid $(N)$ transgene-mediated resistant tobacco indicates that TSWV uses genome reassortment to adapt to new host genotypes (Qiu and Moyer 1999) and more than one viral gene is involved in overcoming the resistance (Qiu et al. 1998). Surprisingly, the partial genetic analysis indicated a primary role for elements on the M RNA rather than the S RNA that encodes the $N$ gene.

In this study, we generated a complete set of reassortants of isolates TSWV-A and TSWV-D. TSWV-A is able to overcome $S w-5$ gene-mediated resistance in tomato and TSWV-N gene-derived resistance in tobacco, whereas TSWV-D is sup- pressed by both forms of resistance. The isolates were stable and genetically distinct as distinguished by the molecular marker system developed previously (Qiu et al. 1998). This system allowed us to address the questions of which viral genome segments carry the element(s) responsible for overcoming the $S w-5$ gene-mediated resistance and which segment(s) of the viral genome may contain the determinants to overcome the transgene silencing in plants transformed with the $N$ gene of TSWV. The complete M RNA sequences from both isolates were compared in an attempt to localize the specific nucleotide sequences responsible for the suppression of resistance.

\section{RESULTS}

\section{Generation and validation of reassortant isolates.}

Reassortant isolates were obtained by coinoculation of the parental isolates TSWV-A and -D on Nicotiana benthamiana. Putative reassortants were passaged through six to ten single, local lesion transfers on $N$. tabacum cv. Burley 21 until only one viral genotype could be detected in the viral progeny. The restriction fragment linked polymorphisms of reverse transcription polymerase chain reaction (RT-PCR)-amplified fragments of the L RNA, M RNA, and S RNA of TSWV-A and $-\mathrm{D}$ are shown in Figure 1A. In addition to TSWV-A, isolates (reassortants) with all six possible combinations of genome segments from TSWV-A and -D were obtained from mixed infections of the two isolates. The genotypes of four representative reassortant are shown in Figure 1B. Where incomplete digestion of PCR products would give ambiguous results, homogeneity was confirmed by alternative restriction endonuclease digestion (Qiu et al. 1998). The parental isolate TSWV-D could not be recovered.

The parental isolates TSWV-A and -D and the six reassortant genotypes were tested for virulence on susceptible Burley 21 and Lycopersicon esculentum cv. Rio Grande. All isolates were able to infect $N$. tabacum, causing local lesions on the inoculated leaf followed by systemic symptoms, including severe stunting, leaf deformation, and necrosis. The susceptible Rio Grande exhibited the typical compatible symptom syndrome, consisting of chlorotic spots on the inoculated leaves and chlorosis, necrosis, and leaf deformation on systemically infected leaves. Tomato plants were severely stunted, and often the shoot tip was deformed. A high degree of uniformity of symptoms across isolates was observed on susceptible tobacco and tomato plants.

\section{Phenotype of reassortants \\ on $S w-5$ gene containing tomato.}

TSWV-A was able to overcome the $S w-5$ gene-mediated resistance, establishing a systemic infection in resistant tomato lines (94c1564 and SW99-1). Symptoms of the systemically infected plants included chlorosis, stunting, and leaf deformation. They were similar to the symptoms expressed from a compatible interaction on the susceptible cultivar Rio Grande after inoculation with TSWV-A or -D. TSWV-D induced necrotic local lesions on the inoculated leaves, but not systemic virus spread, showing that the isolate TSWV-D was suppressed by the $S w-5$ gene.

The ability to overcome the $S w-5$ gene-mediated resistance in tomato was mapped to specific TSWV genome segments 
by inoculating a complete set of reassortant isolates and the parental isolates TSWV-A and -D on two resistant tomato lines. Only TSWV-A and reassortant isolates containing the $\mathrm{M}$ RNA segment from TSWV-A $\left(\mathrm{M}_{\mathrm{A}}\right)$ were able to overcome the resistance by establishing a systemic infection with typical

L

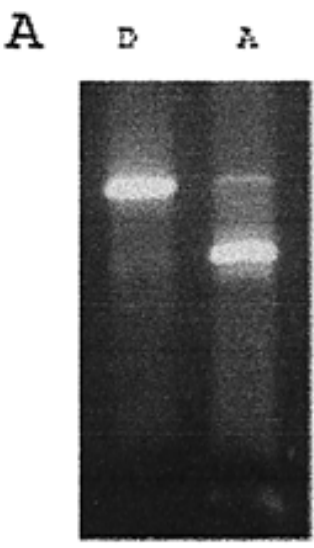

$\mathbf{L}$

\section{B}

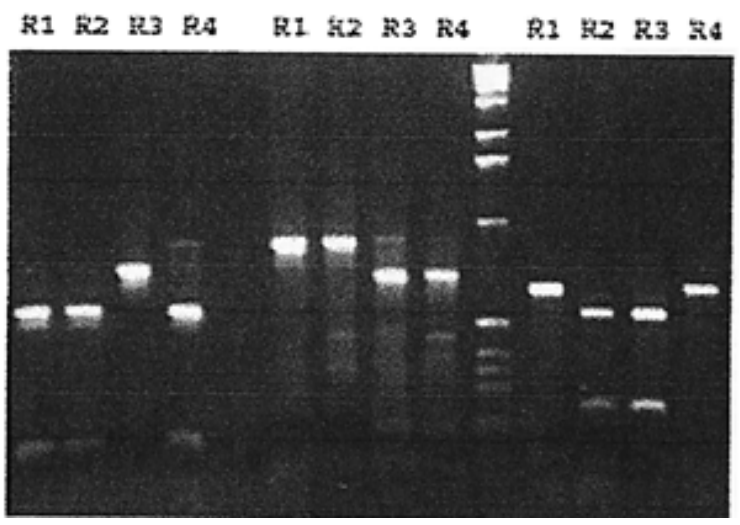

Fig. 1. Restriction fragment polymorphisms of the $L, M$, and $S$ segments from A, TSWV-A and TSWV-D (lanes A and D) and $\mathbf{B}$, representatives of four putative reassortants $\left(\mathrm{R}_{1-4}\right)$. The $\mathrm{L}, \mathrm{M}$, and $\mathrm{S}$ segments were digested with HaeIII, BSTXI, and TaqI, respectively. When incomplete digestion of amplification products prevented verification of isolate purity, homogeneity was confirmed, as described by Qiu et al. 1998. symptoms in both resistant lines (Table 1). Systemic symptoms were similar to those induced on the susceptible tomato cultivar, including leaf chlorosis and deformation as well as stunting, although severity varied among isolates. TSWV-D and all reassortants containing the M RNA segment from TSWV-D $\left(\mathrm{M}_{\mathrm{D}}\right)$ were suppressed by the $S w-5$ gene and not able to induce a systemic infection. Inoculated leaves, however, developed necrotic local lesions on the resistant lines. All isolates with $\mathrm{M}_{\mathrm{D}}$ induced chlorotic local lesions and systemic infections in the susceptible line. For all reassortants, the assessment of viral infection by visual symptoms on the upper noninoculated leaves was confirmed by enzyme-linked immunosorbent assay (ELISA) and inoculation of susceptible host plants such as $N$. tabacum and $N$. benthamiana.

The ability of the parental isolate TSWV-A and all reassortants containing $\mathrm{M}_{\mathrm{A}}$ to overcome the resistance was confirmed with the second tomato genotype (SW99-1), which also contains the $S w-5$ gene (Table 1). After inoculation with the suppressed parental isolate TSWV-D and the reassortants containing $\mathrm{M}_{\mathrm{A}}$, tomato line SW99-1 exhibited virus resistance, as observed with line $94 \mathrm{C} 1564$. At 10 to 14 days postinoculation, a low percentage of SW99-1 plants exhibited systemic symptoms, as expected for a nonisogenic line. The development of a severe necrosis along the stem, petioles, and on the leaves, however, clearly differed from the chlorosis, stunting, and leaf deformation induced on the resistant cultivar after inoculation with the resistance-breaking isolates TSWV-A and $\mathrm{M}_{\mathrm{A}}$ containing reassortants or after systemic infection of the susceptible Rio Grande by TSWV.

An additional experiment was conducted to affirm the role of the $\mathrm{M}_{\mathrm{A}}$ segment with the ability of TSWV to overcome the $S w-5$ gene-mediated resistance in tomato. The resistant and susceptible tomato lines were challenged with TSWV-A and the three reassortants containing $\mathrm{M}_{\mathrm{A}}$, singly or in combination, with TSWV-D. All isolates, single or in combination, caused a typical compatible interaction. The $\mathrm{M}_{\mathrm{A}}$ and $\mathrm{M}_{\mathrm{D}}$ segments could be detected in systemically infected tissue (Fig. 2, lane $3)$. The resistant line challenged with TSWV-A or reassortants containing $\mathrm{M}_{\mathrm{A}}$ also exhibited a typical compatible interaction. Resistant plants that were inoculated with TSWV-D, singly or in combination with the $\mathrm{M}_{\mathrm{A}}$ isolates, exhibited necrotic local lesions and typical systemic symptoms. Only $\mathrm{M}_{\mathrm{A}}$ could be detected in systematically infected leaves of the $S W-5$ containing plants inoculated with isolates containing the $\mathrm{M}_{\mathrm{A}}$ segment, whether inoculated singly or in combination with TSWV-D ( $\left.\mathrm{M}_{\mathrm{D}}\right)$ (Fig. 2 and data not shown). Thus, the ability

Table 1. Phenotypes of reassortant derivatives from TSWV parental isolates TSWV-D and TSWV-A assayed on resistant and susceptible Lycopersicon esculentum and Nicotiana tabacum cv. Burley 21

\begin{tabular}{|c|c|c|c|c|c|}
\hline \multirow[b]{2}{*}{ TSWV genotype ${ }^{a}$} & \multicolumn{3}{|c|}{ L. esculentum } & \multicolumn{2}{|c|}{ N. tabacum } \\
\hline & Susceptible $^{b}$ & Sw-5 gene $94 C 1564$ & Sw-5 gene SW99-1 & Susceptible & $\mathbf{N}$ gene \\
\hline $\mathrm{L}_{\mathrm{D}} \mathrm{M}_{\mathrm{D}} \mathrm{S}_{\mathrm{D}}$ & $14 / 14$ & $0 / 9$ & $0 / 10$ & $14 / 14$ & $1 / 14$ \\
\hline $\mathrm{L}_{\mathrm{A}} \mathrm{M}_{\mathrm{A}} \mathrm{S}_{\mathrm{A}}$ & $14 / 14$ & $9 / 9$ & $10 / 10$ & $14 / 14$ & $14 / 14$ \\
\hline $\mathrm{L}_{\mathrm{A}} \mathrm{M}_{\mathrm{A}} \mathrm{S}_{\mathrm{D}}$ & $14 / 14$ & $9 / 9$ & $10 / 10$ & $14 / 14$ & $14 / 14$ \\
\hline $\mathrm{L}_{\mathrm{D}} \mathrm{M}_{\mathrm{A}} \mathrm{S}_{\mathrm{A}}$ & $14 / 14$ & $4 / 4$ & $10 / 10$ & $14 / 14$ & $12 / 14$ \\
\hline $\mathrm{L}_{\mathrm{D}} \mathrm{M}_{\mathrm{A}} \mathrm{S}_{\mathrm{D}}$ & $14 / 14$ & $4 / 4$ & $10 / 10$ & $14 / 14$ & $10 / 14$ \\
\hline $\mathrm{L}_{\mathrm{A}} \mathrm{M}_{\mathrm{D}} \mathrm{S}_{\mathrm{D}}$ & $14 / 14$ & $0 / 4$ & $3 / 10$ & $14 / 14$ & $0 / 14$ \\
\hline $\mathrm{L}_{\mathrm{D}} \mathrm{M}_{\mathrm{D}} \mathrm{S}_{\mathrm{A}}$ & $14 / 14$ & $0 / 9$ & $3 / 10$ & $14 / 14$ & $0 / 14$ \\
\hline $\mathrm{L}_{\mathrm{A}} \mathrm{M}_{\mathrm{D}} \mathrm{S}_{\mathrm{A}}$ & $14 / 14$ & $0 / 4$ & $1 / 10$ & $14 / 14$ & $3 / 14$ \\
\hline
\end{tabular}

${ }^{a}$ Parental isolates TSWV-A and -D and reassortants. Subscript letters refer to TSWV isolate that was the source of that RNA segment.

${ }^{\mathrm{b}}$ Number systemically infected plants-number of plants inoculated at 10 days postinoculation. 
to overcome the $S w-5$ gene-mediated resistance is not a result of an inability to elicit the hypersensitive response but rather a suppression of or insensitivity to the host resistance response and that the determinant is located on the $\mathrm{M}_{\mathrm{A}}$ segment.

\section{Phenotype of reassortants}

on TSWV $N$ gene containing tobacco.

TSWV-D and -A induced necrotic local lesions on the inoculated leaves of TSWV- $N$ gene-mediated resistant Burley 21. TSWV-A was capable of overcoming the TSWV $N$ genemediated resistance to systemic infection in Burley 21. TSWV-D was suppressed by the presence of the transgene. Systemic infection occurred in a very low percentage of the resistant tobacco plants, but these plants recovered. The resistance was defined by the presence of local lesions on the inoculated leaves and the absence of detectable virus in the noninoculated leaves. After inoculation with the parental isolates TSWV-D and -A, nontransformed tobacco developed necrotic local lesions, followed by a severe systemic infection. Systemic symptoms consisted of leaf chlorosis and necrosis, leaf deformation, and stunting, often leading to the death of the plant.

In order to map the ability to overcome the TSWV $N$ genemediated resistance in Burley 21 to specific viral genome segments, the parental isolates TSWV-D and -A and all reassortant isolates were inoculated on transgenic Burley 21. All reassortants induced necrotic local lesions on the inoculated leaves similar to those induced by the parental isolates. The ability to overcome the $N$ transgene-mediated resistance was observed for reassortants containing the M RNA from TSWVA. Reassortants containing the M RNA segment from TSWVD were suppressed by the $N$ transgene (Table 1). The resistance-breaking isolates can be classified into three major groups on the basis of systemic symptoms on transgenic Burley 21: i) the parental isolate TSWV-A and the reassortants containing the M RNA segment from TSWV-A, in combination with an additional RNA segment from TSWV-A, either the L RMA or S RNA, which were able to overcome the $N$ gene-mediated resistance and cause a severe systemic infection; ii) the reassortants containing only the M RNA segment from TSWV-A and the S RNA and L RNA segment from

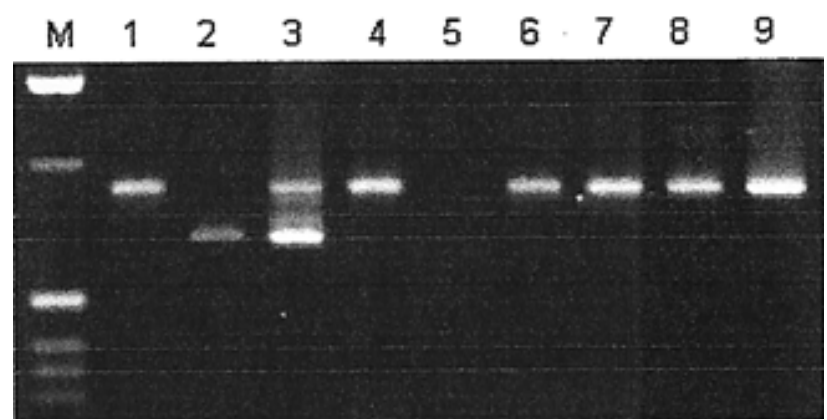

Fig. 2. Origin of the $M$ genome segment detected in systemically infected (or not inoculated, lane 5) leaves of resistant (196SWR) and susceptible (585) tomato plants. Bands in each lane are reverse transcription-polymerase chain reaction amplified from the $M$ segment (lanes 7 and 8 ) and digested with HaeIII (lanes 1 to 6). Lane $\mathrm{M}=1 \mathrm{~KB}$ marker; lanes 1 to 3 and 7 to $9=$ extracts from tomato 585 ; lanes 4 to $6=$ extracts from tomato 196SWR. Extracts from plants inoculated with TSWV-A (lanes 1, 4, and 7), TSWV-D (lanes 2, 5, and 8) or TSWV-A plus TSWV-D (lanes 3, 6, and 9).
TSWV-D, which exhibited an intermediate phenotype and symptom severity was reduced only with mild to moderate systemic symptoms; and iii) the phenotype induced by the reassortants containing the M RNA segment from TSWV-D, which was similar to symptoms caused by the parental isolate TSWV-D. After inoculation with reassortants containing $M_{D}$ and one additional RNA segment from TSWV-D, either $S_{D}$ or $\mathrm{L}_{\mathrm{D}}$, systemic virus spread was suppressed. Reassortant isolates that contain only the M RNA segment from TSWV-D and the L RNA and S RNA segment from TSWV-A showed a very low incidence of systemically infected plants (Table 1). Systemic symptoms were delayed 5 to 7 days and restricted to a necrosis along the midrib of the leaf. Often only a few leaves of the plant were systemically infected, followed by recovery. For the suppressed isolate TSWV-D and reassortants causing mild or transient systemic infection on transgenic Burley 21, local lesions on the inoculated leaves appeared on transgenic Burley 211 to 3 days later than that which occurred on nontransformed Burley 21.

\section{Sequence analysis of M-RNA segments.}

As a result of the major role of the M-RNA segment in overcoming the $S w$-5 gene as well as $N$-gene mediated resistance, the M RNA from the resistance-breaking isolate TSWV-A and the suppressed isolate TSWV-D were cloned and sequenced. Five overlapping clones from each isolate were obtained, spanning the complete M-RNA segment. The length of the entire M RNA segment of TSWV-A and -D was 4,769 and $4829 \mathrm{nt}$, respectively, compared with 4,821 nt for the M RNA of TSWV-BR-01 (Kormelink et al. 1992).

Sequence comparison of the M RNA segments of TSWV-A and $-\mathrm{D}$ and BR-01 revealed multiple differences in the coding and noncoding regions (Table 2). The complete M RNA segment of TSWV-A and -D showed 93.1\% nucleic acid sequence identity; A and BR-01, 92.0\%; and D and BR-01, $95.6 \%$. The $5^{\prime}$ untranslated region (UTR) showed 96\% identity between isolates $\mathrm{A}$ and $\mathrm{D}$ and $97 \%$ between isolates $\mathrm{A}$ and BR-01 and isolates D and BR-01. The 3' UTR exhibited 90.5\% identity between isolates $\mathrm{A}$ and $\mathrm{D}, 90.5 \%$ between isolates A and BR-01, and $100 \%$ between isolates D and BR01. The intergenic region (IGR) had $89.2 \%$ identity for TSWV-A and D, $90.3 \%$ for A and BR-01, and $93.8 \%$ for D and BR-01. The low level of identity in the IGR was mainly a result of major deletions in the M RNA of TSWV-A, leading to an IGR that was 60 and 52 nt shorter than the IGR of TSWV-D and -BR-01, respectively (Table 2). In the deduced amino acid sequence of the NSm ORF, there was a $97.7 \%$ identity between TSWV-A and -D, 96.7\% identity between -A and BR-01, and $97.7 \%$ between -D and BR-01. In the coding region for the G1-G2 ORF, $94.7 \%$ of the amino acids of TSWV-A and -D were identical as were $96.0 \%$ of -A and BR01 and $96.6 \%$ of -D and BR-01 (Table 2).

Alignment of the deduced amino acid sequence of the NSm ORF from TSWV-A and -D showed seven amino acid substitutions (data not shown). All substitutions were located toward the $5^{\prime}$ terminus of the sequence, whereas six occurred within the first 62 of a total 302 amino acids. Both isolates showed one substitution in a potential glycosylation site, serine 30 to asparagine, when compared with TSWV-BR-01 (Kormelink et al. 1992). Alignment of the deduced amino acid sequence of the precursor to the glycoproteins G1-G2 of 
TSWV-A and -D revealed 60 amino acid substitutions that were distributed over the entire length of the 1,135 amino acid sequence. There was no amino acid substitution in the putative cell attachment (RDG motif) site at the $\mathrm{N}$ terminus of the ORF, and only two substitutions for TSWV-D from serine 1,194 to histidine and from glutamic acid 1,195 to lysine in a potential $\mathrm{N}$ glycosylation site at the $3^{\prime}$ proximal sequence of G1-G2 (Kormelink et al. 1992). There was no consistent pattern that would allow identification of the resistance-breaking region in the ORFs or the noncoding regions.

\section{DISCUSSION}

To investigate the molecular basis for overcoming host- and pathogen-derived resistance against TSWV, we have used a genetic system consisting of two genetically distinct TSWV isolates with genome segments distinguishable by molecular markers, as previously described (Qiu et al. 1998). We generated a complete set of reassortants derived from TSWV-A and -D, which differ in their ability to systemically infect resistant host plants. TSWV-A is able to overcome host-derived resistance in tomato, conferred by the resistance gene $S w-5$, and pathogen-derived resistance in Burley 21, mediated by the $N$ gene of TSWV-D, which is repressed by both forms of resistance. Infection of tomato plants containing the $S W-5$ gene was limited to necrotic local lesions on the inoculated leaves (Brommenschenkel and Tanksley 1997), similar to the hypersensitive response described for the defense reaction of $R$ gene-containing host plants (Staskawicz et al. 1995). The $S w$ 5 gene, which is a single, dominant resistance gene (Stevens et al. 1992), was overcome by the isolate TSWV-A. The loss of virulence has been mapped for several gene-for-gene interactions between $R$ and viral genes. In these systems, determinants of the resistance-breaking phenotype mapped to the replicase gene (Meshi et al. 1988), the viral protein-genome linked (VPg) (Nicolas et al. 1997), and the putative cell-to-cell movement protein gene (Meshi et al. 1989). In this study, we showed that the ability to overcome the $S w-5$ gene-mediated resistance maps to the M RNA segment of the isolate TSWVA. This indicates that neither the viral replicase encoded by the L RNA segment nor the N or NSs proteins encoded by the $\mathrm{S}$ RNA segment are involved in breaking the resistance mediated by the $S W-5$ gene. This also is distinct from $t s w$ genemediated resistance in pepper that mapped to the S RNA (Jahn et al. 2000). Although we did not demonstrate that overcoming the $S w-5$ gene-mediated resistance was a result of suppression by elements on the $\mathrm{M}_{\mathrm{A}}$, the resistance was overcome in plants coinoculated with TSWV-D and -A that exhibited the necrotic local lesions associated with initiation of the $R$ gene- type of resistance. This provides evidence that the ability to overcome the resistance is not entirely a result of the failure to initiate the host response. This is consistent with a previous report (Qiu and Moyer 1999), demonstrating that overcoming the $N$ gene-mediated resistance was not a result of a failure to initiate the response.

The M RNA of TSWV encodes two proteins in ambisense orientation, a nonstructural protein $\mathrm{NSm}$ at the $5^{\prime}$ terminal in the viral sense and the precursor of the glycoproteins G1-G2 in viral complementary sense at the $3^{\prime}$ terminal separated by a highly structured intergenic region. The structural proteins G1-G2 reside in the outer envelope of the virion. Interaction of the glycoproteins with proteins of the thrips vector (Bandla et al. 1998; Wijkamp 1995), the loss of thrips transmissibility of envelope-deficient mutants (De Oliveira Resende et al. 1991), and the presence of a sequence motif that is characteristic for cellular attachment domains (Kormelink et al. 1992) provide evidence for the involvement of the glycoproteins in thrips transmission. In addition, G1-G2 have been implicated in particle morphogenesis (Kikkert et al. 1999). The nonstructural protein NSm at the $5^{\prime}$ terminal region of the M RNA segment is associated with nucleocapsid aggregates in the cytoplasm and in close association with plasmodesmata, which suggests its role as a putative viral movement protein (Kormelink et al. 1994). The ability of the NSm protein to induce tubular structures in plant and insect cells provided additional evidence for the involvement of the NSm in cell-tocell movement (Storms et al. 1995; Storms et al. 1998).

Comparison of the deduced amino acid sequence of the coding regions on the M RNA of the resistance-breaking isolate TSWV-A and the repressed isolate TSWV-D revealed $97.7 \%$ identity with seven amino acid substitutions in the NSm and $94.7 \%$ identity with 60 amino acid substitutions in the G1-G2 precursor, respectively. While the amino acid substitutions in the NSm protein were clustered within the first $20 \%$ of the $5^{\prime}$ proximal sequence of NSm, the amino acid substitutions in the G1-G2 precursor were nonuniformly distributed over the entire coding region. Isolated RNA of negativestrand viruses is not infectious, which has inhibited assignment of biological functions to specific viral proteins. Although a "reverse-genetic" system was developed for a bunyavirus, which allowed the rescue of a segmented negativestrand RNA from a cDNA (Bridgen and Elliott 1996), an analogous system has not been developed for TSWV.

Previous research on reassortants of TSWV has shown that the S RNA segments of TSWV differed in their competitiveness during the reassortment process. The distinguishing characteristic of the more competitive S RNA was a shorter IGR (Qiu et al. 1998). In the present study, sequence comparison of

Table 2. Comparison of the nucleotide and amino acid sequences from tomato spotted wilt virus M RNA segments from TSWV-D, A and BR-01

\begin{tabular}{|c|c|c|c|c|c|c|c|c|c|c|c|c|}
\hline \multirow[b]{2}{*}{ Virus $^{a}$} & \multicolumn{2}{|c|}{ Full length } & \multicolumn{2}{|c|}{$3^{\prime}$ untranslated region } & \multicolumn{2}{|c|}{$\mathrm{NSm}$} & \multicolumn{2}{|c|}{ Intergenic region } & \multicolumn{2}{|c|}{ G1-G2 } & \multicolumn{2}{|c|}{$5^{\prime}$ untranslated region } \\
\hline & $\mathbf{A}$ & D & $\mathbf{A}$ & D & $\mathbf{A}$ & D & $\mathbf{A}$ & D & $\mathbf{A}$ & D & $\mathbf{A}$ & D \\
\hline$\overline{\text { BR-01 }}$ & $92.0^{\mathrm{b}}$ & $95.6^{\mathrm{b}}$ & $97.0^{\mathrm{b}}$ & $97.0^{\mathrm{b}}$ & $\begin{array}{l}87.3^{\mathrm{b}} \\
96.7^{\mathrm{c}}\end{array}$ & $\begin{array}{l}91.9^{\mathrm{b}} \\
97.7^{\mathrm{c}}\end{array}$ & $90.3^{\mathrm{b}}$ & $93.8^{\mathrm{b}}$ & $\begin{array}{l}93.3^{\mathrm{b}} \\
96.0^{\mathrm{c}}\end{array}$ & $\begin{array}{l}96.7^{\mathrm{b}} \\
96.6^{\mathrm{c}}\end{array}$ & $90.5^{\mathrm{b}}$ & $100.0^{\mathrm{b}}$ \\
\hline A & & $93.1^{\mathrm{b}}$ & & $96.0^{\mathrm{b}}$ & & $\begin{array}{l}94.3 \\
97.7^{\mathrm{c}}\end{array}$ & & $89.2^{\mathrm{b}}$ & & $\begin{array}{l}93.0^{\mathrm{b}} \\
94.7^{\mathrm{c}}\end{array}$ & & $90.5^{\mathrm{b}}$ \\
\hline
\end{tabular}

\footnotetext{
a Sequence data for isolate TSWV-A (GenBank accession no. AF208498), TSWV-D (GenBank accession no. AF208497) and TSWV-BR-01 (Kormelink et al. 1992).

${ }^{\mathrm{b}}$ Percentage of nucleic acid identity.

c Percentage of amino acid identity.
} 
the M RNA of TSWV-A and -D revealed a difference in the length of $60 \mathrm{nt}$ between the IGR of A and D. After coinoculation of the two parental isolates TSWV-A and -D, the frequency of the possible combinations of genome segments of the parental isolates was determined. From 30 progeny isolates, 24 were reassortants and six represented the parental phenotype TSWV-A. The M RNA segment was contributed by TSWV-A in $87 \%$ of the progeny isolates (data not shown), indicating a possible involvement of the length of the IGR in the reassortment process as shown for the S RNA (Qiu et al. 1998). The IGR is predicted to form a stable-stem loop structure and is thought to be involved in initiation and termination of transcription (Kormelink et al. 1992; Law et al. 1992). These results are consistent with our previous report on the $S$ RNA (Qiu et al. 1998), indicating that the IGR of the S RNA influences the competitiveness of the individual segment in mixed populations.

The transformation of Burley 21 with the $N$ gene of TSWVD conferred resistance against systemic infection with the homologous and a range of other (but not all) TSWV isolates (Herrero et al. 2000). $N$ gene-mediated resistance is defined here by the absence of symptoms on the upper noninoculated leaves, whereas plants developed necrotic local lesions on the inoculated leaves. After inoculation with the resistancebreaking isolate TSWV-A, the transgenic Burley 21 plants exhibited necrotic local lesions on the inoculated leaves, followed by severe systemic symptoms, including leaf deformation, stunting, leaf chlorosis, and necrosis. Transgenemediated resistance against TSWV includes a homologydependent, posttranscriptional gene-silencing mechanism (Pang et al. 1996; Prins et al. 1997). A relationship between gene silencing and some forms of natural virus resistance has been proposed (Brigneti et al. 1998; Covey et al. 1997; Ratcliff et al. 1997) on the basis of the observation that natural resistance against Cauliflower mosaic virus in Brassica spp. (Covey et al. 1997) and Tomato black ring virus infection in nontransgenic Nicotiana spp. (Ratcliff et al. 1997) also involves posttranscriptional gene silencing. Recently it was shown that the helper component-proteinase of Potato virus $Y$ and Tobacco etch virus or the $2 \mathrm{~b}$ protein of Cucumber mosaic virus has the capacity to suppress posttranscriptional gene silencing (Anandalakshmi et al. 1998; Brigneti et al. 1998; Kaschau and Carrington 1998), indicating that gene silencing might represent a general antiviral defense mechanism (Brigneti et al. 1998). In our study, we were able to show that the major determinant overcoming TSWV $N$ gene-mediated resistance was located on the M RNA segment of the resistance-breaking isolate TSWV-A (Table 1). This is an unexpected finding because the $N$ gene is located on the S RNA.

This report and our previous research (Qiu et al. 1998; Qiu et al. 1999) agree with investigations of potyviruses (Kaschau and Carrington 1998) that provided evidence that more than one element of the viral genome was involved in the suppression of the resistance response. As shown in Table 1, defeating the resistance associated with the M RNA was enhanced by the presence of the L RNA and S RNA segment of the resistance-breaking isolate TSWV-A. These data correlate well with observations by Qiu et al. (1998), who isolated a TSWV reassortant that was able to overcome transgene-mediated resistance. This reassortant was recovered from a mixed infection of two isolates, TSWV-D and -10 , on a susceptible host plant and contained the L RNA and M RNA segments from TSWV-10 and the S RNA segment from the isolate TSWV-D ( $\mathrm{L}_{10} \mathrm{M}_{10} \mathrm{~S}_{\mathrm{D}}$ ) (Qiu et al. 1998). It is noteworthy that both parental isolates were repressed by the transgenemediated resistance conferred by the $N$ gene of TSWV-D. This supports the hypothesis that two viral genes are involved in suppression of resistance because elements from both isolates were necessary to suppress the resistance (Qiu et al. 1998). The results of the present study also indicate that the suppression of transgene silencing could be a combined effect of different viral genome segments, although elements on the M RNA played a major role. These results also question the focus on the $N$ gene, located on the $\mathrm{S}$ segment, for increasing the durability of $N$ gene-mediated resistance to TSWV because even though the $N$ gene mediates the resistance, it is the M RNA that contains the primary element for suppression of resistance.

\section{MATERIALS AND METHODS}

\section{Host plants and TSWV isolates.}

Two different accessions of $L$. esculentum that exhibited resistance to TSWV conferred by the $S w-5$ gene were provided by Seminis Seeds (Woodland, CA, U.S.A.). Line a (94c1564) exhibited a higher level of resistance than line b (SW99-1). Rio Grande served as a susceptible control. To confirm initial results, a second experiment was conducted with 196SWR as the resistant tomato line and 585 as the susceptible parent. After germination, tomato seedlings were transplanted to 10$\mathrm{cm}$ clay pots. Tomato transplants were kept under greenhouse conditions in natural light at approximate temperatures of $30^{\circ} \mathrm{C}$ day $-20^{\circ} \mathrm{C}$ night, respectively. Burley 21 plants transformed with the $N$ gene of TSWV-D (Herrero et al 2000) were used in the transgene resistance study and compared with nontransformed control plants.

Two TSWV isolates were used as parents to generate reassortants. TSWV-A (regular 2) was isolated from a resistant tomato cultivar and able to overcome the $S w-5$ gene-mediated resistance. TSWV-D isolated from dahlia (dahlia $\times$ hybrida) and originating from The Netherlands was suppressed by the $S w-5$ gene and the TSWV-N gene. The parental isolates as well as the reassortant isolates were maintained in Emilia sonchifolia plants. Tissue from systemically infected $N$. benthamiana plants was frozen at $-80^{\circ} \mathrm{C}$. Parental isolates and reassortant isolates were passaged once through $N$. benthamiana to obtain highly concentrated inoculum for mechanical inoculation of tomato and tobacco plants.

\section{Generation of reassortant isolates.}

Equal amounts of inoculum of TSWV-A and -D were mixed and coinoculated on $N$. benthamiana. Systemically infected leaves were then used for inoculation of Burley 21. Single local lesions on Burley 21 were passaged three to six times over $N$. tabacum to select and segregate putative reassortants according to their local lesion type, shape, and time of appearance. Putative reassortants were then inoculated on $N$. benthamiana for subsequent extraction of total RNA to determine the origin of the genome segments. Reassortant isolates were validated on the basis of uniformity of symptoms and detection of genome segments by molecular markers (Qiu et al. 1998). 


\section{Molecular marker system.}

Total plant RNA was extracted from 100 to $150 \mathrm{mg}$ of systemically infected leaves from $N$. benthamiana with the RNA Isolater (Genosys, Woodland, TX, U.S.A.), following the manufacturer's protocol. An aliquot of the RNA extract was used as template in the cDNA synthesis according to the protocol supplied for avian myeloblastosis virus reverse transcriptase (Promega, Madison, WI, U.S.A.). First-strand cDNA was extracted by phenol-chloroform and precipitated in ethanol. The cDNA was subsequently used as template for PCR amplification. Specific regions on each genome segment were amplified with the primer pair L4856-L5578 for the L RNA, M66-M962 for the M-RNA, and S1983-S2767 for the S RNA under the conditions and PCR programs previously described (Qiu et al. 1998). PCR products were then subjected to restriction enzyme digestion with HaeIII for the L RNA fragment, BstXI for the M RNA fragment, and TaqI for the S RNA fragment. PCR products and restriction fragments were visualized on $1 \%$ agarose gel and photographed after staining with ethidium bromide.

\section{Parental and reassortant phenotypes on tomato and tobacco.}

Parental isolates and all reassortant genotypes were mechanically inoculated on susceptible and resistant tomato plants at the two-true-leaf stage. To enhance inoculation efficiency, tomato seedlings were kept under low-light intensity $24 \mathrm{~h}$ before inoculation. TSWV $N$ gene-containing and nontransformed Burley 21 were mechanically inoculated with the parental and reassortant isolates at the two-leaf stage. Symptoms were monitored at 2-day intervals and recorded up to 4 weeks postinoculation. In addition, viral infections were confirmed by ELISA with TSWV polyclonal antibodies (Hoffmann et al. 1998).

\section{Cloning and sequencing of the M-RNA.}

Viral RNA was extracted from purified virus (Law et al. 1992) of TSWV-A and -D and used as template for RT-PCR amplification of the M RNA segment. RT-PCR fragments were cloned in a pGEM-T vector (Promega). Clones containing cDNA fragments of the M RNA were sequenced. Nucleotide and protein sequences were analyzed by Wisconsin Package Software (Genetics Computer Group, Madison, WI, U.S.A).

\section{ACKNOWLEDGMENTS}

We greatly acknowledge J. J. Cho (University of Hawaii, HI, U.S.A.) for providing the resistance-breaking isolate TSWV-A (regular 2A) and Seminis Seeds, Woodland, CA, U.S.A for providing TSWV resistant and susceptible tomato seeds.

\section{LITERATURE CITED}

Adam, G., Yeh, S.-D., Reddy, D. V. R., and Green, S. K. 1993. Serological comparison of tospovirus isolates from Taiwan and India with impatiens necrotic spot virus and different tomato spotted wilt virus isolates. Arch. Virol. 130:237-250.

Adkins, S., Quadt, R., Choi, T.-J., Ahlquist, P., and German, T. 1995. An RNA-dependent RNA polymerase activity associated with virions of tomato spotted wilt virus, a plant-infecting bunyavirus. Virology 207:308-311.

Adkins, S., Choi, T.-J., Israel, B. A., Bandla, M. D., Richmond, K. E., Schulz, K. T., Sherwood, J. L., and German, T. L. 1996. Baculovirus expression and processing of tomato spotted wilt tospovirus glycoproteins. Phytopathology 86:849-855.

Anandalakshmi, R., Pruss, G. J., Ge, X., Marathe, R, Mallory, A. C., Smith, T. H., and Vance, V. B. 1998. A viral suppressor of gene silencing in plants. Proc. Natl. Acad. Sci. USA 95:13079-13084.

Bandla, M. D., Campell, L. R., Ullman, D. E., and Sherwood, J. L. 1998. Interaction of tomato spotted wilt tospovirus (TSWV) glycoproteins with a thrips midgut protein, a potential cellular receptor for TSWV. Phytopathology 88:98-104.

Best, R. J. 1954. Cross protection by strains of tomato spotted wilt virus and a new theory to explain it. Aust. J. Biol. Sci. 7:415-424.

Best, R. J. 1968. Tomato spotted wilt virus. Pages 65-145 in: Advances in Virus Research, K. M. Smith and M. A. Lauffer, eds. Academic Press, New York.

Best, R. J., and Gallus, H. P. C. 1953. Strains of tomato spotted wilt virus. Aust. J. Sci. 15:212-214.

Boiteux, L. S., and De B. Giordano, L. 1993. Genetic basis of resistance against two tospovirus species in tomato (Lycopersicon esculentum). Euphytica 71:151-154.

Bridgen, A., and Elliott, R. M. 1996. Rescue of a segmented negativestrand RNA virus entirely from cloned complementary DNAs. Proc. Natl. Acad. Sci. USA 93:15400-15404.

Brigneti, G., Voinnet, O., Li, W.-X., Ji, L.-H., Ding, S.-W., and Baulcombe, D. C. 1998. Viral pathogenicity determinants are suppressors of transgene silencing in Nicotiana benthamiana. EMBO J. 17:6739-6746.

Brommenschenkel, S. H., and Tanksley, S. D. 1997. Map-based cloning of the tomato genomic region that spans the $S w-5$ tospovirus resistance in tomato. Mol. Gen. Genet. 256:121-126.

Cho, J. J., Mau, R. F. L., German, T. L., Hartmann, R. W., Yudin, L. S., Gonsalves, D., and Provvidenti, R. 1989. A multidisciplinary approach to management of tomato spotted wilt virus in Hawaii. Plant Dis. 73:375-383.

Cho, J. J., Custer, D. M., Brommonschenkel, S. H., and Tanksley, S. D. 1996. Conventional breeding: Host-plant resistance and the use of molecular markers to develop resistance to tomato spotted wilt virus. Acta Hortic. 431:367-378.

Covey, S. N., Al-Kaff, N. S., Langara, A., and Turner, D. S. 1997. Plants combat infection by gene silencing. Nature 385:781-782.

De Avila, A. C., De Haan, P., Kormelink, R., De Resende, R., Goldbach, R. W., and Peters, D. 1993. Classification of tospoviruses based on phylogeny of nucleoprotein gene sequences. J. Gen. Virol. 74:153-159.

De Haan, P., Wagemakers, L., Peters, D., and Goldbach, R. 1990 The S RNA segment of tomato spotted wilt virus has an ambisense character. J. Gen. Virol. 71:1001-1007.

De Haan, P., Kormelink, R., De Oliveira Resende, R., Van Poelwijk, F., Peters, D., and Goldbach, R. 1991. Tomato spotted wilt virus L RNA encodes a putative RNA polymerase. J. Gen. Virol. 71:2207-2216.

De Oliveira Resende, R., De Haan, P., De Avila, A. C., Kitajima, E. W., Kormelink, R., Goldbach, R., and Peters, D. 1991. Generation of envelope and defective interfering RNA mutants of tomato spotted wilt virus by mechanical passage. J. Gen. Virol. 72:2375-2383.

Elliott, R. M. 1990. Molecular biology of the bunyaviridae. J. Gen. Virol. 71:501-522.

Elliott, R. M. 1996. The bunyaviridae: Concluding remarks and future prospects. Pages 295-332 in: The Bunyaviridae. R. M. Elliott, ed. Plenum Press, New York.

Feldhoff, A., Kikkert, M., Kormelink, R., Krczal, G., Goldbach, R., and Peters, D. 1997. Serological comparison of tospoviruses with polyclonal antibodies produced against the main structural proteins of tomato spotted wilt virus. Arch. Virol. 142:781-793.

Folkertsma, R. T., Spassova, M. I., Prins, M., Stevens, M. R., Hille, J., and Goldbach, R. W. 1999. Construction of a bacterial artificial chromosome (BAC) library of Lycopersicon esculentum cv. Stevens and its application to physically map the $S w-5$ locus. Mol. Breed. 5:197-207.

German, T. L., Ullman, D. E., and Moyer, J. W. 1992. Tospoviruses: Diagnosis, molecular biology, phylogeny, and vector relationships. Ann. Rev. Phytopathol. 30:315-348.

Gielen, J. J. L., De Haan, P., Kool, A. J., Peters, D., Van Griensven, M. Q. J. M., and Goldbach, R. 1991. Engineered resistance to tomato spotted wilt virus, a negative-strand RNA virus. Bio/Technology 9:1363-1367.

Goldbach, R., and De Haan, P. 1993. Prospects of engineered forms of resistance against tomato spotted wilt virus. Semin. Virol. 4:381-387. 
Herrero, S., Culbreath, A. K., Csinos, A. S., Pappu, H. R., Rufty, R. C., and Daub, M. E. 2000. Nucleocapsid gene-mediated transgenic resistance provides protection against Tomato spotted wilt virus epidemics in the field. Phytopathology 90:139-147.

Hobbs, H. A., Black, L. L., Johnson, R. R., and Valverde, R. A. 1994. Differences in reactions among tomato spotted wilt virus isolates to three resistant Capsicum chinense lines. Plant Dis. 78:1220 (Abstr.).

Hoffmann, K., Geske, S. M., and Moyer, J. W. 1998. Pathogenesis of tomato spotted wilt virus in peanut plants dually infected with peanut mottle virus. Plant Dis. 82:610-614.

Jahn, M., Paran, I., Hoffmann, K,. Radwanski, E. R,. Livingstone, K. D, Grube, R. C, Aftergoot, E., Lapidot, M., and Moyer, J. 2000. Genetic mapping of the Tsw locus for resistance to tomato spotted wilt Tospovirus Tomato spotted wilt virus in Capsicum spp. and its relationship to the $S w-5$ gene0 for resistance to the same pathogen in tomato. Mol. Plant-Microbe Interact. 13:673-682.

Jankulova, M., Karadjova, O., Atanassov, A., and Adam, G. 1999. Identifizierung und charakterisierung von tospoviren in Bulgarien. In: Plant Virus Working Group, German Phytopathological Society, Freising, Germany.

Kaschau, K. D., and Carrington, J. C. 1998. A counterdefensive strategy of plant viruses: Suppression of posttranscriptional gene silencing. Cell 95:461-470.

Kikkert, M., Van Lent, J., Storms, M., Bodegom, P., Kormelink, R., and Goldbach, R. 1999. Tomato spotted wilt particle morphogenesis in plant cells. J. Virol. 73:2288-2297.

Kim, J. W., Sun, S. S. M., and German, T. L. 1994. Disease resistance in tobacco and tomato plants transformed with the tomato spotted wilt virus nucleocapsid gene. Plant Dis. 78:615-621.

Kormelink, R., De Haan, P., Meurs, C., Peters, D. and Goldbach, R. 1992. The nucleotide sequence of the M RNA segment of tomato spotted wilt virus, a bunyavirus with two ambisense RNA segments. J. Gen. Virol. 73:2795-2804.

Kormelink, R., Storms, M., Van Lent, J., Peters, D., and Goldbach, R. 1994. Expression and subcellular location of the NSm protein of tomato spotted wilt virus (TSWV), a putative viral movement protein. Virology 200:56-65.

Latham, L. J., and Jones, R. A. C. 1998. Selection of resistance breaking strains of tomato spotted wilt tospovirus. Ann. Appl. Biol. 133:385-402.

Law, M. D., and Moyer, J. W. 1990. A tomato spotted wilt-like virus with a serologically distinct N protein. J. Gen. Virol. 71:933-938.

Law, M. D., Speck, J., and Moyer, J. W. 1991. Nucleotide sequence of the 3' non-coding region and $\mathrm{N}$ gene of the $\mathrm{S}$ RNA of a serologically distinct tospovirus. J. Gen. Virol. 72:2597-2601.

Law, M. D., Speck, J., and Moyer, J. W. 1992. The M RNA of impatiens necrotic spot tospovirus (Bunyaviridae) has an ambisense genomic organization. Virology 188:732-741.

MacKenzie, D. and P. J. Ellis, 1992: Resistance to tomato spotted wilt virus infection in transgenic tobacco expressing the viral nucleocapsid gene. Mol. Plant-Microbe Interact. 5:34-40.

Meshi, T., Motoyoshi, F., Adachi, A., Watanabe, Y., Takamatsu, N., and Okada, Y. 1988. Two concomitant base substitutions in the putative replicase genes of tobacco mosaic virus confer the ability to overcome the effects of a tomato resistance gene, Tm-1. EMBO J. 7:1575-1581.

Meshi, T., Motoyoshi, F., Maeda, T., Yoshiwoka, S., Watanabe, H., and Okada, Y. 1989. Mutations in the tobacco mosaic virus $30-\mathrm{kD}$ protein gene overcome Tm-2 resistance in tomato. Plant Cell 1:515-522.

Moury, B., Palloix, A., Selassie, K. G., and Marchoux, G. 1997. Hypersensitive resistance to tomato spotted wilt virus in three Capsicum chinense accessions is controlled by single gene and overcome by virulent strains. Euphytica 94:45-52.

Nicolas, O., Dunnington, S. W., Gotow, L. F., Pirone, T. P., and Hellmann, G. M. 1997. Variations in the VPg protein allow a potyvirus to overcome $v a$ gene resistance in tobacco. Virology 237:452-459.

Norris, D. O., 1946. The strain complex and symptoms development of spotted wilt virus. Aust. C. S. I. R. O. Bull. No. 202.

Pang, S.-Z., Nagpala, P., Wang, M., Slightom, J. L., and Gonsalves, D. 1992. Resistance to heterologous isolates of tomato spotted wilt virus isolates in transgenic tobacco expressing its nucleocapsid protein gene. Phytopathology 82:1223-1229.

Pang, S.-Z., Bock, J. H., Gonsalves, C., Slightom, J. L., and Gonsalves, D. 1994. Resistance of transgenic Nicotiana benthamiana plants to tomato spotted wilt and impatiens necrotic spot tospoviruses: Evidence of involvement of the $\mathrm{N}$ protein and $\mathrm{N}$ gene RNA in resistance.
Phytopathology 84:243-249.

Pang, S.-Z., Jan, F.-J., Carney, K., Stout, J., Tricoli, D. M., Quemada, H. D., and Gonsalves, D. 1996. Post-transcriptional transgene silencing and consequent tospovirus resistance in transgenic lettuce are affected by transgene dosage and plant development. Plant J. 9:899-909.

Pang, S.-Z., Jan, F.-J., and Gonsalves, D. 1997. Nontarget DNA sequences reduce the transgene length necessary for RNA-mediated tospovirus resistance in transgenic plants. Proc. Natl. Acad. Sci. USA 94:8261-8266.

Paterson, R. G., Scott, S. J., and Gergerich, R. C. 1989. Resistance in two Lycopersicon species to an Arkansas isolate of tomato spotted wilt virus. Euphytica 43:173-178.

Prins, M., De Oliviera Resende, R., Anker, C., Van Schepen, A., De Haan, P., and Goldbach, R. 1996. Engineered RNA-mediated resistance to tomato spotted wilt virus is sequence specific. Mol. Plant-Microbe Interact. 9:416-418.

Prins, M., Kikkert, M., Ismayadi, C., De Graauw, W., De Haan, P., and Goldbach, R. 1997. Characterization of RNA-mediated resistance to tomato spotted wilt virus in transgenic tobacco plants expressing the $\mathrm{NS}_{\mathrm{m}}$ gene sequences. Plant Mol. Biol. 33:235-243.

Qiu, W., and Moyer, J. W. 1999. Tomato spotted wilt tospovirus adapts to TSWV N gene-derived resistance by genome reassortment. Phytopathology 89:575-582.

Qiu, W., Geske, S. M., Hickey, C. M., and Moyer, J. W. 1998. Tomato spotted wilt tospovirus genome reassortment and genome segmentspecific adaptation. Virology 244:186-194.

Ratcliff, F., Harrison, B. D., and Baulcombe, D. C. 1997. A similarity between viral defense and gene silencing in plants. Science 276:1558-1560.

Samuel, G., Bald, J. G., and Pittman, H. A. 1930. Spotted wilt of tomatoes. Aust. C. S. I. R. O. Bull. No. 44

Sherman, J. M., Moyer, J. W., and Daub, M. E. 1998. Tomato spotted wilt virus resistance in Chrysanthemum expressing the viral nucleocapsid gene. Plant Dis. 82:407-414.

Smith, P. G. 1944. Reaction of Lycopersicon spp. to spotted wilt. Phytopathology 34:504-505.

Staskawicz, B. J., Ausubel, F. M., Baker, B. J., Ellis, J. G., and Jones, J. D. G. 1995. Molecular genetics of plant disease resistance. Science 268:661-667.

Stevens, M. R., Scott, S. J., and Gergerich, R. C. 1992. Inheritance of a gene for resistance to tomato spotted wilt virus (TSWV) from $L y$ copersicon peruvianum Mill. Euphytica 59:9-17.

Stevens, M. R., Lamb, E. M., and Rhoads, D. D. 1995. Mapping the $S w$ 5 locus for tomato spotted wilt virus resistance in tomatoes using RAPD and RFLP. Theor. Appl. Genet. 90:451-456.

Storms, M. M. H., Kormelink, R., Peters, D., Van Lent, J. W. M., and Goldbach, R. W. 1995. The nonstructural NSm protein of tomato spotted wilt virus induces tubular structures in plant and insect cells. Virology 214:485-493.

Storms, M. M. H., Van der Schoot, C., Prins, M., Kormelink, R., Van Lent, J. W. M., and Goldbach, R. W. 1998. A comparison of two methods of microinjection for assessing altered plasmodesmal gating in tissues expressing viral movement proteins. Plant J. 13:131-140.

Ullman, D. E., German, T. L., Sherwood, J. L., Westcot, D. M., and Cantone, F. A. 1993. Tospovirus replication in insect vector cells: Immunocytochemical evidence that the nonstructural protein encoded by the S RNA of tomato spotted wilt tospovirus is present in thrips vector cells. Phytopathology 83:456-463.

Ultzen, T., Gielen, J., Venema, F., Westerbroek, A., De Haan, P., Tan, M.-L., Schram, A., Van Grinsven, M., and Goldbach, R. 1995. Resistance to tomato spotted wilt virus in transgenic tomato hybrids. Euphytica 85:159-168.

Vaira, A. M., Semeria, L., Crespi, S., Lisa, V., Allavena, A., and Accotto, G. P. 1995. Resistance to tospoviruses in Nicotiana benthamiana transformed with the $\mathrm{N}$ gene of tomato spotted wilt virus: Correlation between transgene expression and protection in primary transformants. Mol. Plant-Microbe Interact. 8:66-73.

Van Poelwijk, F., Prins, M., and Goldbach, R. 1997. Completion of the impatiens necrotic spot virus genome sequence and genetic comparison on the $\mathrm{L}$ proteins within the family Bunyaviridae. J. Gen. Virol. 78:543-546.

Wijkamp, I. 1995. Virus-vector relationships in the transmission of tospoviruses. Ph.D. diss. Agricultural University, Wageningen, The Netherlands.

Wijkamp, I., Van Lent, J., Kormelink, R., Goldbach, R., and Peters, D 1993. Multiplication of tomato spotted wilt virus in its insect vector, Frankliniella occidentalis. J. Gen. Virol. 74:341-349. 